\title{
TUNAS
}

JURNAL PENDIDIKAN GURU SEKOLAH DASAR

UMP

http://journal.umpalangkaraya.ac.id/index.php/tunas Volume 5 Nomor 1, Desember 2019 (36-43)

\section{INTERNALISASI FALSAFAH RUMAH BETANG UNTUK MEMBENTUK SIKAP TOLERANSI}

\section{Internalization Of Falsafah Betang Houses To Form A Tolerance Attitude}

'Roso Sugiyanto, ${ }^{2}$ Abdul Rahman Azahari, ${ }^{3}$ Wawan Kartiwa dan ${ }^{4}$ Sapriline

Universitas Palangka Raya, Palangka Raya, Kalimantan Tengah, Indonesia

2 Universitas Palangka Raya, Palangka Raya, Kalimantan Tengah, Indonesia

3 Universitas Palangka Raya, Palangka Raya, Kalimantan Tengah, Indonesia

4 Universitas Palangka Raya, Palangka Raya, Kalimantan Tengah, Indonesia

ARTIKEL INFO

Diterima

November 2019

Dipublikasi

Desember 2019

*e-mail :

rososugiyanto@gm

ail.com

\section{ABSTRAK}

Rumah betang atau huma betang adalah rumah adat suku Dayak khas Kalimantan Tengah yang terdapat di berbagai daerah Kalimantan Tengah. Rumah Betang di bangun dalam bentuk panggung dengan ketinggian tiga sampai lima meter dari tanah dengan panjang bangunan mencapai 150meter dan lebar hingga 30 meter. Nilai-nilai yang terkandung dalam Huma Betang sangat dijunjung tinggi oleh masyarakat dan menjadi pedoman dalam kehidupan sehari-hari oleh masyarakat Kalimantan Tengah. Selain berfungsi sebagai rumah adat, Huma Betang memiliki filosofi kehidupan yang sangat dalam dan mendasar bagi masyarakat seperti nilai gotong royong, kebersamaan, toleransi, rukun, dan hidup berdampingan. Gotong royong dan kerukunan sebagai nilai yang mapan dan terpelihara hingga saat ini. Manfaat dari eksistensi dan implementasi falsafah Huma Betang terhadap kehidupan bermasyarakat, berbangsa, dan bernegara, beberapa diantaranya adalah Huma Betang sebagai refleksi kehidupan masyarakat yang toleran (togetherness in diversity). Rekontruksi nilainilai huma betang dalam kehidupaan saat ini sangat diperlukan khususnya dalam rangka menyambut wacana pemindahan ibu kota negara Indonesia. Revitalisasi budaya dapat dimulai dari pengangkatan nilai-nilai kearifan lokal, salah satunya dari filosofi rumah adat Huma Betang. Revitalisasi dan implementasi falsafah huma betang dapat dilakukan dengan secara formal dilakukan melalui pembelajaran berbasis etnopedagogik pada mata pelajaran muatan lokal, secara informal dilakukan melalui pola perilaku keteladanan guru. Untuk membentuk karakter siswa yang berasazkan falsafah rumah betang yang baik harus terdapat tiga komponen yaitu moral knowing, (pengetahuan tentang moral), moral feeling (perasaan tentang moral) dan moral action (perbuatan moral).

Kata kunci: Falsafah Rumah Betang, Sikap Toleransi.

\section{ABSTRACT}

Betang house or Huma Betang is a traditional house of Dayak tribe typical of Central Kalimantan, which is found in various regions of Central Kalimantan. Betang house was built in the form of a stage with a height of three to five meters from the ground with a building length of 150 meters and a width of up to 30 meters. The values contained in Huma Betang are highly valued by the community and serve as guidelines in daily life by the people of Central Kalimantan. Aside from functioning as a traditional house, Huma Betang has a very deep and fundamental philosophy of life for the community such as mutual cooperation, togetherness, tolerance, harmony, and coexistence. Mutual cooperation and harmony as an established value and maintained until now. The benefits of the existence and implementation of Huma Betang's philosophy on social, national and state life, some of which are Huma Betang as a reflection of community life that is tolerant (togetherness in diversity). Reconstruction of the value of Betang Huma in life today is very necessary, especially in order to welcome the discourse of moving the Indonesian capital. Cultural revitalization can begin with the promotion of local wisdom values, one of which is the philosophy of the Huma Betang traditional house. Revitalization and implementation of Huma Betang philosophy can be done formally through ethnopedagogic-based learning on local content subjects, informally carried out through teacher exemplary behavior patterns. To form the character of students who express the philosophy of a good betang house, there must be three components, namely moral knowing, (moral knowledge), moral feeling (moral feeling) and moral action (moral action).

Keywords: Betang House Philosophy, Tolerance..

(C) Universitas Muhammadiyah Palangkaraya 


\section{Jurnal Pendidikan Guru Sekolah Dasar PENDAHULUAN}

Pengaruh globalisasi sangat besar terhadap eksistensi budaya pada kehidupan sekarang ini. Salah satunya budaya huma betang, saat ini sudah mulai ditinggalkan hanya beberapa keluarga saja yang masih bermukim di sana. Apalagi dikota-kota Kalimantan Tengah banyak rumah-rumah masyarakat yang dibangun dengan model modern dan minimalis yang berbanding terbalik dengan bangunan huma betang. Rumah Betang atau huma betang adalah rumah adat Suku Dayak khas Kalimantan Tengah yang terdapat di berbagai daerah Kalimantan Tengah, terutama di daerah hulu sungai yang biasanya menjadi pusat pemukiman suku Dayak. Rumah Betang di bangun dalam bentuk panggung dengan ketinggian tiga sampai lima meter dari tanah dengan panjang bangunan mencapai 150 meter dan lebar hingga 30 meter. Secercah harapan dan kebanggan, ternyata masih ada tradisi dan budaya yang diabstraksikan seperti abstraksi dari interaksi dalam rumah betang yang masih dipertahankan dalam alam pemikiran masyarakat Dayak. Pertanyaan penting yang patut diajukan adalah apakah falsafah huma betang itu mampu menjawab tantangan terhadap pemindahan ibu kota pemerintahan Republik Indonesia? Ataukah memang falsafah huma betang ini sengaja dibuat resisten dengan mengatasnamakan integrasi?

Beberapa pertanyaan tadi penting menjadi tujuan dari telaah ini, yaitu mengkaji falsafah huma betang dan peran guru dalam menanamkan falsafah huma betang pada anak-anak untuk menjawab tantangan perpindahan ibukota negara. Upaya tersebut tentunya dengan mencari dan mendalami berbagai pandangan mengenai budaya huma betang yang dikonstruksikan oleh masyarakat Dayak sendiri, dikenal sebagai pandangan tahan lama, tidak bisa diruntuhkan, mengakar. Falsafah yang ada pada huma betang tersebut akan diinternaslisasikan ke anak-anak agar menyatu menjadi karakter anak masyarakat
Dayak. Internalisasi karakter yang berasal dari falsafah huma betang tersebut diharapkan mampu menjadi solusi jika anak-anak dihadapkan dengan persoalan-persoalan yang muncul atau mengemuka dengan adanya penduduk yang heterogen karena perpindahan ibukota pemerintahan Republik Indonesia.

Guru menjadi bagian dari sistem pendidikan yang akan berperan penting dalam menginternalisasikan nilai-nilai falsafah rumah betang pada anak-anak disekolah. Sistem pendidikan yang mampu mengembangkan pribadi yang memiliki karakter baik, yang secara personal dan sosial siap menjalani dunianya seharusnya menjadi tujuan utama setiap institusi pendidikan. Sistem pendidikan yang sesuai untuk menghasilkan kualitas yang cerdas dan berakhlak mulia adalah yang bersifat humanis dan memposisikan peserta didik sebagai pribadi dan sekaligus sebagai anggota masyarakat yang perlu dibantu dan didorong agar memiliki kebiasaan efektif, perpaduan antara keinginan, pengetahuan, dan ketrampilan (Darmiyati Zuchdi, 2009: 6). Perpaduan tersebut secara harmonis menyebabkan seseorang atau suatu kelompok meninggalkan ketergantungan menuju kemandirian dan saling ketergantungan. Salingketergantungan sangat diperlukan dalam kehidupan yang semakin kompleks dan hanya dapat diatasi secara kolaboratif sehingga diperlukan keterampilan membangun hubungan yang serasi.

Keseluruhan uraian di atas memberikan penegasan bahwa anak-anak akan tumbuh menjadi pribadi yang berkarakter baik apabila tumbuh dalam lingkungan sosial yang berkarakter juga, dan memerlukan kesadaran dari seluruh pihak yang mempengaruhi kehidupan anak yaitu keluarga, sekolah, dan masyarakat. Sehubungan dengan hal tersebut, diharapkan sekolah-sekolah di Kalimantan Tengah sebagai salah satu pihak yang bertanggung jawab atas pembentukan kepribadian 
Jurnal Pendidikan Guru Sekolah Dasar

anak seharusnya segera mengambil langkah untuk menerapkan atau menanamkan/ menginternalisasikan falsafah rumah betang sebagai kepribadian/ karakter anak-anak di Kalimantan Tengah. Sehubungan adanya komitmen melaksanakan internalisasi karakter, hal ini sama artinya dengan mendukung pencapaian Pendidikan nasional itu sendiri. Menurut pasal 3 Undang-Undang No. 20 tahun 2003 bahwa tujuan pendidikan nasional adalah untuk mengembangkan kemampuan dan membentuk watak serta peradaban bangsa yang bermartabat dalam rangka mencerdaskan kehidupan bangsa, bertujuan untuk berkembangnya potensi peserta didik agar menjadi manusia yang beriman, bertaqwa kepada Tuhan yang Maha Esa, berakhlak mulia, sehat, berilmu, cakap, kreatif, mandiri, dan menjadi warga negara yang demokratis serta bertanggung jawab (Depdiknas, 2003:52)

Sekolah selain mengajarkan pengetahuan juga harus mengajarkan kebaikan untuk membentuk peserta didik yang berkarakter/ berkepribadian. Pendidikan karakter mempunyai tiga bagian yang saling berhubungan yaitu moral knowing, moral feeling, dan moral behavior (Lickona, 199I: 5I). Kesuksesan pendidikan karakter sangat bergantung pada ada tidaknya knowing the good, loving/ desiring the good, dan doing/acting. Pendidikan karakter bergerak dari knowing, menuju doing sampai acting.

Rumah betang memiliki nilai-nilai positif yang perlu dilestarikan dan dikembangkan untuk menjaga keharmonisan hidup baik dalam keluarga, sekolah, masyarakat, berbangsa dan bernegara. Berdasarkan pemaparan di atas Tujuan dari telaah ini, yaitu mengkaji falsafah budaya rumah betang dan bagaimana cara menginternalisasikannya pada anak-anak untuk menjawab tantangan perpindahan ibu kota pemerintahan Republik Indonesia.

\section{METODOLOGI PENELITIAN}

Artikel ini termasuk jenis artikel ilmiah non penelitian, karena itu teknik penulisan yang digunakan adalah teknik studi pustaka, yaitu mengkaji bahan-bahan pustaka yang berhubungan dengan pendidikan dalam hubungannya dengan budaya. Pernyataan tersebut sesuai dengan pendapat Roth (Mestika, 2008) yang menyebutkan "untuk melakukan studi kepustakaan, perpustakaan merupakan suatu tempat yang tepat guna memperoleh bahan-bahan dan informasi yang relevan untuk dikumpulkan, dibaca dan dikaji, dicatat dan dimanfaatkan”. Dengan demikian pustaka yang dikaji untuk menyusun tulisan ini adalah sumber-sumber pustaka yang berhubungan dengan "Peran Pendidik, rumah betang dan karakter". Menurut Hasan (2002) pelaksanaan studi kepustakaan dilakukan melalui 3 (tiga) tahap, yaitu: I. Mengetahui jenis pustaka, yang dibutuhkan, 2. Mengkaji dan mengumpulkan bahan pustaka, dan 3. Menyajikan studi kepustakaan. Pada tahap pertama penulis menetukan sumber pustaka baik sumber tertulis dan sumber tidak tertulis. Selanjutnya pada tahap kedua adalah melakukan kajian dan pengumpulan bahan pustaka yang biasa disebut bibliografi atau kartu kutipan. Kemudian tahap yang terakhir adalah memaparkan atau menyajikan hasil kajian pustaka itu sendiri baik dalam bentuk kutipan langsung maupun dalam bentuk kutipan tidak langsung.

\section{HASIL DAN PEMBAHASAN}

\section{A. Falsafah Rumah Betang}

Filosofi merupakan suatu kebenaran yang dianggap benar. Untuk diketahui bahwa filosofi Huma Betang (Rumah Betang) di Kalimantan Tengah sangat menjunjung tinggi perdamaian dan anti-kekerasan serta hidup toleransi yang tinggi antar-umat beragama, Farada (Ibnu Elmi, 2018). Falsafah huma betang merupakan salah satu budaya yang tumbuh dan berkembang pada masyarakat Dayak di Kalimantan Tengah. Rumah 
Jurnal Pendidikan Guru Sekolah Dasar betang/ huma betang tidak hanya menjadi bangunan fisik tempat tinggal masyarakat Suku Dayak saja akan tetapi menjadi bangunan jantung dari struktur sosial kehidupan. Struktur sosial utama adalah adanya nilai yaitu kebersamaan di dalam perbedaan (together in diversity), artinya ada semangat kesatuan dan persatuan, etos kerja dan toleransi yang tinggi untuk mengelola secara bersama-sama segala perbedaan yang ada dan mampu berkompetisi secara jujur sehingga perbedaan yang ada menjadi sebuah kekuatan untuk bersatu bukan sebagai jurang pemisah.

Nilai-nilai yang terkandung dalam rumah betang sangat dijunjung tinggi oleh masyarakat dan menjadi pedoman dalam kehidupan sehari-hari oleh masyarakat Kalimantan Tengah. Selain berfungsi sebagai rumah adat, rumah betang memiliki filosofi kehidupan yang sangat dalam dan mendasar bagi masyarakat seperti nilai gotong royong, kebersamaan, toleransi, rukun, dan hidup berdampingan. Berikut nilai-nilai yang terkandung dalam rumah betang.

I. Hapahari

Hapahari diartikan sebagai persaudaraan dan kebersamaan dalam kehidupan di rumah betang. Menurut Ibnu Elmi, (2018) rumah betang dihuni oleh satu keluarga besar yang terdiri dari berbagai agama dan kepercayaan, namun mereka selalu hidup rukun dan damai. Perbedaan yang ada tidak dijadikan alat pemecah diantara mereka artinya dalam hal ini falafah dalam rumah betang adalah "Hidup Rukun dan Damai Walau Terdapat Banyak Perbedaan”. Secara filosofis budaya huma betang di Kalimantan Tengah menggambarkan kebersamaan dalam keberagaman. Hidup bersama dengan berbagai keberadaan masing-masing individu yang memiliki karakter yang berbedabeda. Pada dasarnya pelaksanaan konsep hapahari memegang prinsip bahwa tamu adalah raja, sebagi contoh sederhana mereka menghargai orang luar atau tamu dengan berusaha memberikan kepuasan kepada tamu tersebut, walaupun kondisi mereka dalam keadaan keterbatasan. Perlakuan terhadap orang lain di luar komunitas betang memang mendapat tanggapan yang positif dari warga masyarakat lainnya yang bukan Dayak. Mereka ikut merasakan bagaimana perlakuan komunitas betang yang pada prinsipnya menganggap bahwa orang lain adalah pahari.

\section{Handep}

Kearifan betang yang tidak pernah sirna adalah handep yang diartikan sebagai sikap saling membantu atau tolong-menolong secara bergantian, pandohop (bantuan), saling mandohop (membantu). Handep biasanya terlihat secara konkret pada upacara kematian (tiwah), upacara perkawinan, membuka lahan atau ingin menanam padi, serta upacara-upacara adat lainnya. Semangat tolong-menolong yang tinggi dalam komunitas betang dinampakkan dalam handep. Menurut Ibnu Elmi, (2018) Perbedaan yang ada tidak membuat penghuni Huma Betang memikirkan kelompoknya sendiri. Mereka selalu bahumembahu dalam melakukan sesuatu, misalnya apabila ada kerusakan di Huma Betang. Mereka bersama-sama memperbaikinya, tidak memandang agama ataupun suku. Handep dilakukan dalam segalahal segi kehidupan dimana pekerjaan tersebut tidak dapat dilakukan sendiri tapi membutuhkan pertolongan warga betang lainnya. Untuk melakukan handep diperlukan hati yang bersih dan penuh kasih, jauh dari kebencian dan kedengkian agar pekerjaan yang berat menjadi ringan ketika dikerjakan bersama dengan sukacita dan ketulusan.

\section{Belom Bahadat}

Belom bahadat artinya adalah hidup beradab dan memiliki etika, dipahami oleh komunitas betang sebagai aturan atau tata krama yang mengatur kehidupan bersama, yaitu menghargai adat yang berlaku dalam wilayah komunitas adat yang bersangkutan. Dalam rumah betang ini setiap kehidupan individu dalam rumah tangga dan masyarakat diatur melalui kesepakatan bersama 
Jurnal Pendidikan Guru Sekolah Dasar

yang dituangkan dalam hukum adat. Dengan hidup beradab dan beretika, maka akan tercipta suatu system kehidupan yang rukun dan damai.

4. Hapakat Kula

Hapakat kula (saling bermufakat) merupakan ciri khas kehidupan para penghuni rumah betang. Setiap penghuni rumah menginginkan kedamaian dan kekeluargaan, apabila ada perselisihan akan di cari pemecahnya dengan cara damai dan kekeluargaan dengan mengedepankan musyawarah dan mufakat. Putusan dari musyawarah dan mufakat tersebut, diambil sebagai kesepakatan bersama yang harus dijalankan dengan benar.

\section{B. Internalisasi Falsafah Huma Betang pada Anak Sekolah}

Pengembangan kepribadian anak-anak disekolah dengan menginternalisasi falsafah rumah betang pada sekolah-sekolah di Kalimantan Tengah sama konsepnya dengan pelaksanaan pendidikan karakter. Pendidikan karakter disekolah menganjurkan hubungan yang saling menghoramati sehingga para siswa dan pegawai bisa bekerja bersama-sama untuk mencapai tujuan bersama. Di sekolah seharusnya terjadi hubungan yang saling memedulikan sehingga semua anggota komunitas merasa menjadi bagian dari kelompok. Sekolah harus memberikan peluang kepada siswa untuk melakukan kerjasama yang sering dalam komunitas sekolah itu. Hal demikian ini seperti dikatakan oleh Athur (2003:I I9) bahwa:

"The development of character naturally takes place within communities, such as schools, which encourage respectful relationships so that pupils and staff work together to meet common purposes. These relationships in a school should be caring relationships which help all to feel that they belong as full members of a community. This means schools need to design opportunities for pupils to collaborate on a frequent basis".

Internalisasi falsafah rumah betang mestinya mengikuti langkah-langkah yang sistematis, dimulai dari pengenalan nilai secara kognitif, langkah memahami dan menghayati nilai secara afektif, dan langkah pembentukan tekad secara konatif. Internalisasi karakter siswa seharusnya menjadi bagian dari program lembaga sekolah, yang dirancang dalam kerjasama dengan lembaga komunitas yang lain dengan tujuan untuk membentuk secara langsung dan sistematis perilaku anak muda (siswa) dengan memberikan pengaruh secara nyata kepada mereka berupa nilai-nilai yang tidak relatif (nilai yang bersifat absolut) yang diyakini memperbaiki prilaku seperti falsafah rumah betang, seperti yang diungkapkan oleh Nucci dan Narvaez, (2008: 90)

"Character education can be defined as any schoolinstituted program, designed in cooperation with other community institution, to shape directly and systematically the behavior of young people by influencing explicitly the non-relativistic values believed directly to bring about that behavior".

Jadi, pendidikan karakter (internalisasi falsafah rumah betang) merupakan program sekolah namun dalam pelaksanaannya dilakukan secara kerjasama dengan keluarga dan masyarakat. Ini menunjukkan bahwa kegiatan internalisasi falsafah rumah betang tidak berdiri sendiri sebagai kewajiban dari sekolah saja akan tetapi melibatkan unsur di luar sekolah yaitu keluarga dan masyarakat. Tanpa keterlibatan orang tua dan keluarga maka sebaik apapun nilainilai yang diajarkan di sekolah akan menjadi sia-sia.

Menurut Muhaimin (1996: 153), proses internalisasi dalam pembinaan peserta didik atau anak asuh ada tiga tahap yang mewakili proses atau tahap terjadinya internalisasi yaitu:

I. Tahap transformasi nilai, tahap ini merupakan suatu proses yang akan dilakukan oleh pendidik dalam menginformasikan nilai-nilai yang baik, kurang baik dan nlai tercela. Pada tahap ini hanya terjadi komunikasi verbal anatar pendidik dan pesert didik.

2. Tahap transaksi nilai, yaitu tahap Pendidikan nilai dengan jalan melakukan 


\section{TUNAS}

Jurnal Pendidikan Guru Sekolah Dasar komunikasi dua arah, atau interaksi antara peserta didik dengan pendidik yang bersifat interaksi timbal-balik.

3. Tahap traninternalisasi, tahap ini jauh lebih mendalam dari tahap transaksi. Pada tahap ini bukan hanya dilakukan dengan komunikasi verbal akan tetapi juga siap mental dan kepribadian, jadi pada tahap ini komunikasi kepribadian yang berperan secara aktif.

Kirchenbaum (1995: 3I) menyatakan bahwa pendidikan karakter (internalisasi falsafah rumah betang) seharusnya dilaksanakan dengan pendekatan secara komprehensif yang meliputi inkulkasi nilai, keteladanan nilai, fasilitasi nilai, dan pengembangan ketrampilan. Keteladanan nilai merupakan pemberian teladan oleh guru. Guru mempunyai peran yang sangat penting untuk memberikan model yang ideal dan memfasilitasi anak dalam pemerolehan pendidikan karakter (memahami dan menghayati falsafah rumah betang). Guru adalah contoh nyata yang bisa ditiru oleh murid (ing ngarso sung tuladha). Selain contoh dalam pembelajaran yang dilakukan, guru haruslah mempunyai cara-cara yang bagus atau metode pembelajaran yang tepat dalam kegiatan belajar mengajar di sekolah, sehingga anak bisa mengadopsi nilai-nilai falsafah rumah betang yang terintegrasi dalam proses pembelajaran yang dengan sengaja diberikan agar siswa menjadi lebih baik.

Menurut Licona (1991:5I) Pendidikan karakter bergerak dari knowing, menuju doing, atau acting. Penyebab ketidakmampuan seseorang berlaku baik, meskipun telah memiliki pengetahuan tentang kebaikan itu (moral knowing) adalah karena tidak terlatih untuk melakukan kebaikan (moral doing). Berangkat dari pemikiran tersebut maka kesuksesan pendidikan karakter sangat bergantung pada ada tidaknya knowing, loving, dan doing atau acting dalam penyelenggaraan internalisasi falsafah rumah betang. Falsafah rumah betang akan menjadi karakter atau kepribadian siswa di Kalimantan Tengah tidak sebatas pengetahuan saja tetapi menjangkau wilayah emosi dan kebiasaan diri. Berdasarkan kajian ditemukan ada tiga tahapan sekaligus komponen yang harus dilakukan dalam menginternalisasikan falsafah rumah betang. Tahapan dan komponen yang dimaksud meliputi moral knowing, (pengetahuan tentang moral), moral feeling (perasaan tentang moral) dan moral action (perbuatan moral).

\section{Moral knowing}

Tahapan ini merupakan langkah pertama yang harus dilaksanakan dalam penyelenggaraan internalisasi falsafah rumah betang. Pada tahap ini siswa diharapkan mampu membedakan nilai yang baik dan nilai-nilai yang tidak baik (tercela). Siswa juga diharapkan mampu memahami secara logis dan rasional tentang pentingnya karakter sebagai cerminan kepribadiaan seseorang, selain itu siswa diharapkan mampu menemukan sosok atau model yang bias dijadikan panutan.

Moral knowing sebagai aspek pertama memiliki enam unsur yaitu kesadaran moral (moral awareness), pengetahuan tentang nilai-nilai moral (knowing moral values), penentuan sudut pandang (persepective taking), logika moral (moral reasoning), keberanian mengambil sikap (dicision making), dan pengenalan diri (self knowledge). Keenam unsur adalah komponen-komponen yang harus diajarkan kepada siswa untuk mengisi ranah kognitif (Licona, I 991:53).

\section{Moral loving atau feeling}

Tahapan kedua ini dimaksudkan untuk menumbuhkan rasa cinta dan rasa butuh terhadap nilai-nilai falsafah rumah betang dan juga memiliki kemampuan menilai dirinya sendiri atau intropeksi diri. Pada tahap ini guru harus bisa menjangkau dimensi emosional siswa, hati dan jiwa siswa. Moral loving atau feeling merupakan pengetahuan aspek emosi siswa-siswa di Kalimantan Tengah untuk menjadi manusia yang 


\section{TUNAS}

Jurnal Pendidikan Guru Sekolah Dasar

berkarakter/ berkepribadian berasazkan falsafah rumah betang. Penguatan ini berkaitan dengan bentuk-bentuk sikap yang harus dirasakan oleh siswa, yaitu kesadaran akan jati diri, percaya diri (self esteem), kepekaan terhadap derita orang lain (emphaty), cinta kebenaran (loving the good), pengendalian diri (self control), kerendahan hati/ humanity (Licona, 1991:53).

\section{Moral acting sebagai outcome}

Tahap ini merupakan puncak keberhasilan dalam internalisasi falsafah rumah betang pada siswa, yakni ketika siswa sudah mampu mempraktikannya dalam kehidupan sehari-hari secara sadar. Jika seseorang mempunyai kualitas moral secara intelektual maupun secara emosi, maka orang tersebut sepertinya akan melakukan apa yang diketahui dan dirasa sebagai sesuatu yang benar. Lickona (I99I:6I) menyebutkan bahwa dalam mentransformasikan apa yang diketahui dan dirasa harus dilakukan menjadi suatu tindakan nyata memerlukan waktu yang tidak sebentar. Menurut Licona ada tiga aspek karakter yang menjadikan seseorang melakukan tindakan moral, yaitu: kompetensi (competence), keinginan (will), dan kebiasaan (habit). Ketiga tahapan pendidikan karakter di atas harus diberikan melalui cara-cara yang logis, rasional, dan demokratis. Ketiga komponen karkter seperti yang dikemukakan oleh Lickona diatas adalah konten dari masingmasing nilai yang diajarkan dalam pendidikan karakter.

\section{SIMPULAN}

Berdasarkan pembahasan dapat disimpulkan sebagai berikut; (I) secara filosofi, budaya huma betang di Kalimantan Tengah menggambarkan kebersamaan dalam keberagaman. Nilai-nilai yang terkandung dalam Huma Betang sangat dijunjung tinggi oleh masyarakat dan menjadi pedoman dalam kehidupan sehari-hari oleh masyarakat
Kalimantan Tengah. Selain berfungsi sebagai rumah adat, Huma Betang memiliki filosofi kehidupan yang sangat dalam dan mendasar bagi masyarakat seperti Hapahari (persaudaraan dan kebersamaan), Handep (tolong-menolong), Belom Bahadat (hidup beradab dan memiliki etika), dan Hapakat Kula (saling bermufakat). (2) Untuk membentuk karakter siswa yang berasazkan falsafah rumah betang yang baik terdapat tiga tahapan sekaligus komponen yaitu moral knowing, (pengetahuan tentang moral), moral feeling (perasaan tentang moral) dan moral action (perbuatan moral).

\section{DAFTAR PUSTAKA}

Athur, James. (2003). Education with character: The moral economy of schooling. London: RoutledgeFalmer

Darmiyati Zuchdi. (2009). Humanisasi pendidikan: Menemukan kembali pendidikan yang manusiawi. Jakarta: Bumi Aksara.

Departemen Pendidikan Nasional. (2003). Undang-Undang RI Nomor 20, Tahun 2003, Tentang Sistem Pendidikan Nasional.

Hasan. 2002. Metode Penelitian. Bogor: Ghalia Indonesia.

Ibnu Elmi AS Pelua, Jefry Tarantang. 2018. Interkoneksi Nilai-Nilai Huma Betang Kalimantan Tengah dengan Pancasila. Jurnal Studi Agama dan Masyarakat.

Kirchenbaum, H. (1995). 100 ways to enchance values and morality in two schools and youth setting. Boston: Allyn and Bacon.

Lickona, Thomas. (1991). Educating for character. How our school can teach respect and responsibility. New York: Bantam Books.

Mestika. 2008. Metodo penelitian kepustakaan. Jakarta: Yayasan Obor Indonesia.

Muhaimin. 1996. Strategi Belajar Mengajar. Surabaya: Citra media. 


\section{TUNAS}

Jurnal Pendidikan Guru Sekolah Dasar

Nucci, Larry P. \& Narvaez, Darcia [Eds.]. (2008).

Handbook of moral and character education.

New York: Routledge.

'Roso Sugiyanto, ${ }^{2} \mathrm{Abdul}$ Rahman Azahari, ${ }^{3}$ Wawan Kartiwa dan ${ }^{4}$ Sapriline P-ISSN 2477-6076 